\title{
EGF Protects Epithelial Cells from Barrier Damage in Chronic Rhinosinusitis with Nasal Polyps
}

\author{
Le Chen ${ }^{1,2}$ \\ Quan Liu ${ }^{1,2}$ \\ Zhuofu Liu' ${ }^{1,2}$ \\ Han Li ${ }^{1,2}$ \\ Xiang Liu ${ }^{1,2}$ \\ Hongmeng $\mathrm{Yu}^{1,2}$ \\ 'Department of Otolaryngology, Eye \& ENT \\ Hospital, Fudan University, Shanghai, \\ 20003I, People's Republic of China; \\ ${ }^{2}$ Research Units of New Technologies of \\ Endoscopic Surgery in Skull Base Tumour, \\ Chinese Academy of Medical Sciences, \\ 20I8RU003, Shanghai, People's Republlc of \\ China
}

Background: The aim of this study is to investigate the potential key genes related to Chronic rhinosinusitis with nasal polyps (CRSwNP).

Methods: Datasets GSE36830 and GSE72713 were obtained from Gene Expression Omnibus. Dataset GSE36830 was used to identify differentially expressed genes in CRSwNP patients. GO, KEGG analysis, and PPI network analysis were applied to further investigate the function of DEGs in CRSwNP. GSEA was also performed to explore the mechanisms of DEGs. Dataset GSE72713 was applied to validate the key gene. Moreover, to detect the expression of target gene, nasal polyp tissues and middle turbinate specimens were collected from CRSwNP patients $(\mathrm{n}=20)$ and controls $(\mathrm{n}=20)$, respectively. RT-PCR, Western blot, and immunofluorescence staining were applied. HE and AB-PAS staining were used to assess the infiltration of inflammatory cells. The proliferation and migration ability of human nasal epithelial cells (HNEpCs) were tested via Cell Counting kit-8, wound healing assay and Transwell migration assay. Air-liquid interface was used to culture primary human nasal epithelial cells (pHNECs) from health controls and nasal polyp tissues of CRSwNP patients.

Results: A total of 1035 DEGs were identified, and 661 genes were up-regulated and 374 genes were down-regulated. According to PPI network analysis, the top 10 scored genes were identified. Among them, only EGF was down-regulated in CRSwNP. Meanwhile, GSEA result shows that EGF is significantly enriched in WNT activated receptor activity. CCK-8, wound healing assay, and transwell migration assay indicated that recombinant human EGF can promote the proliferation and migration of HNEpCs in vitro. Immunofluorescence staining shows that rhEGF can increase the expression of ZO-1 in pHNECs from nasal polyp tissues.

Conclusion: Bioinformatics analysis and in vitro experiments were used to explore the pathogenesis of CRSwNP, and the results showed that EGF may play an important role in the protection of nasal epithelial barrier.

Keywords: chronic rhinosinusitis with nasal polyps, bioinformatics analysis, GSEA, EGF, epithelial barrier

\section{Introduction}

Chronic rhinosinusitis (CRS) is a common chronic nasal mucosa inflammation disease, which affects approximately $7 \%$ to $27 \%$ of adult population. ${ }^{1-3}$ It is a group of heterogeneous diseases with common symptoms but different pathogenesis. ${ }^{4,5}$ Based on the presence or absence of nasal polyps (NP), CRS has been divided into CRS with NP (CRSwNP) and CRS without NP (CRSsNP). ${ }^{6}$ CRSwNP is characterized by the nasal obstruction and inflammation of the nasal mucosa, which seriously reduces the quality of life of patients. ${ }^{7-10}$ The etiologies of
Correspondence: Hongmeng Yu; Xiang Liu Email hongmengyush@163.com;

liuxiangat@|26.com 
CRSwNP have been investigated worldwide and extraor-

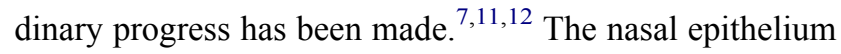
is the physical and immune barrier, and its dysfunction is an outstanding feature of CRSwNP. ${ }^{13-18}$ Epithelial cells play an important role in innate immune, and it can produce protective proteins and resist microbial invasion. ${ }^{19-22}$ Meng et al revealed that the expression levels of ZO-1, E-cadherin, and occludin were down-regulated in mature polyps, and epithelial damage was most obviously in early stage. $^{23}$ Meanwhile, several studies have reported the decreased expression of ZO-1, E-cadherin and occludin in polyps. ${ }^{23-28}$ It is currently believed that the regeneration and repairment of epithelium are changed in patients with CRSwNP, and the reduced barrier function of epithelium is a potent contributing factor to type 2 immunity. ${ }^{29-32}$ However, the mechanisms underlying CRSwNP are not fully defined. Therefore, to develop a novel treatment for CRSwNP, further investigation is needed.

High throughput sequencing is an increasingly important field. It has been widely applied in biological research. In the present study, the differentially expressed genes (DEGs) of nasal epithelium between CRSwNP patients and healthy individuals were analyzed based on the microarray datasets downloaded from the Gene Expression Omnibus (GEO) database. In the dataset GSE36830, Seshadri et al collected nasal tissues from patients with skull base tumor and patients with CRS. ${ }^{11}$ Gene Ontology (GO) process, Kyoto Encyclopedia of Genes and Genomes (KEGG) pathway analysis, protein-protein interaction (PPI) networks, and Gene set enrichment analysis (GSEA) were performed to identify the key genes and pathways associated with CRSwNP in the dataset GSE36830. Dataset GSE72713 was downloaded and applied to validate the identified potential target gene in dataset GSE36830. ${ }^{33}$ Moreover, cell biology experiments were used to investigate the effects of target gene in CRSwNP. As far as we know, the present study is one of the first to integrate GSEA and biological experiments to explore the mechanism involved in CRSwNP.

\section{Methods}

\section{Microarray Data Processing}

Dataset GSE36830 acquired from the GEO database was used to identify the key genes related to CRS. The platform of GSE36830 dataset was GPL570 (Affymetrix Human Genome U133 Plus 2.0 Array). This dataset included NP tissues from 6 subjects with CRSwNP, uncinate tissues (UT) from 6 subjects with CRSsNP and 6 control subjects. To validate the target gene, dataset GSE72713 was downloaded. In dataset GSE72713, the data of total RNA was extracted from NP tissues of 6 CRSwNP patients and sphenoid sinus mucosa of 3 normal controls.

\section{Identification of DEGs}

$\mathrm{R}$ software (version 3.5.2, United States) was used to normalize the raw microarray data of GSE36830. The "limma" package in R software was carried out to identify the DEGs between the NP tissues of CRSwNP patients and the health controls. In addition, the DEGs between the UT tissues of the CRSsNP patients and the NP tissues of CRSwNP patients, and the UT tissues of the CRSwNP patients and the NP tissues of CRSwNP patients were identified. $|\log \mathrm{FC}|$ (fold change) $>1$ and $p<0.05$ were considered as statistical significance.

\section{Construction of the PPI Networks}

The Search Tool for the Retrieval of Interacting Genes (STRING) platform was used to construct the PPI networks of DEGs in different groups. The value of the correlation between proteins was set to greater than 0.4 . Cytohubba, a plug-in of Cytoscape software (version 3.7.1, UAS) was applied to identify the top 10 key genes of connectivity of DEGs in different groups.

\section{GO and KEGG Analyses}

Database for Annotation, Visualization, and Integrated Discovery (DAVID) is usually used for functional analysis of genes and proteins. To further investigate the function of DEGs between the NP tissues of CRSwNP patients and the health controls, DAVID was applied to carry out the GO process and KEGG pathway analyses. False discovery rate $(\mathrm{FDR})<0.05$ was set as the cutoff point.

\section{Gene Sets Enrichment Analysis (GSEA)}

To further investigate the pathogenesis of CRSwNP, GO analysis of all genes of the NP tissues of CRSwNP and the health controls in GSE36830 was carried out by GSEA software (version 4.0.3, USA). This analysis can explore the major pathway that the target genes involved in.

\section{Patients and Specimens}

The tissue samples were obtained from patients in the Department of Otolaryngology-Head and Neck Surgery, 
Eye, Ear, Nose, and Throat (Eye \& ENT) Hospital of Fudan University. The normal control middle turbinate tissues were obtained from the patients $(\mathrm{n}=20)$ who underwent skull base tumor excision or optic nerve decompression operation and had no history of upper airway inflammatory diseases. NP tissues were obtained from CRSwNP patients $(\mathrm{n}=20)$ who underwent functional endoscopic sinus surgery. The exclusion criteria were as follows: age $<18$ or $>80$ years, a diagnosis of cystic fibrosis, immunodeficiency, aspirin intolerance, autoimmune disease, Churg-Strauss syndrome, asthma, or fungal sinusitis. This study complies with the Declaration of Helsinki and was approved by the Eye \& ENT Hospital and all subjects gave informed consent.

\section{Extraction of Total RNA and Quantitative RT-PCR}

For extraction of total RNA, NP tissues and middle turbinate tissues were homogenized with $1 \mathrm{~mL}$ Trizol Reagent according to the guidelines. The complementary DNA (cDNA) template was synthesized with PrimeScript RT Master mix (TaKaRa, Japan). Then, the mRNA expression of the target gene was analyzed using an RT-PCR Sequence Detection System (ABI, USA) with SYBR Green chemistry (TaKaRa, Japan). The specific RT-PCR primer for EGF: forward 5' GAAGCATTGGACAAGTATGCAT -3 ', reverse 5'-CAGC TTCTGAGTCCTGTAGTAG-3'. The relative expression level of the target gene was analyzed using the $2^{-\Delta \Delta C T}$ method. $^{34}$

\section{Western Blot}

Protein samples $(20 \mu \mathrm{g})$ obtained from frozen NP tissues and middle turbinate tissues were resolved by $10 \%$ sodium dodecyl sulfate polyacrylamide gel electrophoresis (SDSPAGE) and transferred onto polyvinylidene difluoride membranes (PVDF) (Millipore, USA). Then, it was incubated with anti-EGF antibody (1:700, Santa, USA) according to manufacturer's protocol. The expression of $\beta$-actin (1:2000, Abcam, UK) was detected as an internal control. Densitometric analysis of the data was performed by Image J software (NIH, USA).

\section{Histological Staining}

To detect the infiltration of eosinophils and the hyperplasia of the mucous cells in the NP tissues and health controls, hematoxylin and eosin (HE) and Alcian blue-periodic acid Schiff (AB-PAS) staining were applied, as previously published. ${ }^{35-39}$ Slices were examined under microscope, and the number of eosinophils and mucous cells in different stainings were counted in 5 random high-power fields.

\section{Immunofluorescence Staining}

Briefly, slices were incubated with anti-tryptase antibody (1:100, Santa, USA) and anti-EGF antibody (1:700, Santa, USA) at $4^{\circ} \mathrm{C}$ overnight, and then incubated with the secondary antibody at room temperature for $2 \mathrm{~h} .{ }^{40}$ Immunofluorescence samples were observed and photographed with an inverted microscope (Leica, Germany). Image J software (NIH, USA) was used to analyze the mean fluorescence intensity.

\section{Cell Culture}

Human nasal epithelial cell (HNEpC) line was obtained from American Type Culture Collection (ATCC, USA). HNEpCs were cultured in RPMI1640 (Gibco, USA), supplemented with $10 \%$ fetal bovine serum (Gibco, USA) and $1 \%$ penicillin-streptomycin (Gibco, USA). Cells were cultured at $37^{\circ} \mathrm{C}$ with $5 \% \mathrm{CO}_{2}$ atmosphere.

\section{Cell Proliferation Assay}

Approximately $2 \times 10^{3}$ HNEpCs were cultured on 96-well culture plates in $100 \mu \mathrm{L}$ of RPMI1640 medium with $10 \%$ FBS and $1 \%$ penicillin-streptomycin. HNEpCs were cultured for 1 4 days at $37^{\circ} \mathrm{C}$ with $5 \% \mathrm{CO}_{2}$ atmosphere. For EGF treatment group, cells were cultured with the above medium containing $100 \mathrm{ng} / \mathrm{mL}$ recombinant human EGF (rhEGF, PeproTech, USA). The proliferation was detected by Cell Counting Kit-8 (CCK-8) assay kit (Dojindo, Japan) according to the manufacturer's instructions. Briefly, $10 \mu \mathrm{L}$ of CCK-8 solution was added to each well for $1 \mathrm{~h}$ incubation, and the absorbance of the test wells was measured by using a microplate reader at $450 \mathrm{~nm}$.

\section{Wound Healing and Transwell Migration Assays}

HNEpCs were seeded into 6-well culture plates. To form an artificial wound, cell monolayers were scraped off with a 200 $\mu \mathrm{L}$ pipette tip. After scratching, to remove the detached cells and residual serum, the wells were washed three times with PBS and then serum-free 1640 medium was added. For EGF treatment group, cells were cultured with 1640 medium containing $50 \mathrm{ng} / \mathrm{mL}$ and $100 \mathrm{ng} / \mathrm{mL}$ rhEGF. The wound healing of HNEpCs was imaged with an inverted microscope (Leica, Germany) at $0 \mathrm{~h}, 24 \mathrm{~h}$ and $48 \mathrm{~h}$. 
The migration of HNEpCs was investigated in Transwell chambers ( $8-\mu \mathrm{m}$ pore filters, Corning, USA). Approximately $1 \times 10^{4}$ cells suspended in $100 \mu \mathrm{L}$ serumfree 1640 medium were placed in the upper chamber, and $600 \mu \mathrm{L} 1640$ medium which contains 10\% FBS or $10 \%$ FBS and $50,100 \mathrm{ng} / \mathrm{mL}$ rhEGF was added to the lower chamber, respectively. After $24 \mathrm{~h}$ and $48 \mathrm{~h}$, the cells on the lower surface of the chamber were fixed, stained, and counted.

\section{Primary Human Epithelial Cell Culture and rhEGF Stimulation}

Primary human epithelial cells (pHNECs) were isolated from the above nasal tissues. Briefly, nasal samples were immediately immersed in DPBS $\left(\mathrm{Ca}^{2+} / \mathrm{Mg}^{2+}\right.$-free $)$ supplemented with $1 \%$ penicillin, streptomycin, and amphotericin B (all reagents from Gibco). After washed three times, nasal tissues were digested with $0.1 \%$ Protease XIV (Sigma-Aldrich) overnight at $4^{\circ} \mathrm{C}$. After filtering, all cells were immersed in DMEM/F12 media (Gibco, USA) which contains $10 \%$ FBS and 1\% ITS for $2 \mathrm{~h}$ at $37{ }^{\circ} \mathrm{C}$ with $5 \% \mathrm{CO}_{2}$ atmosphere. Next, cells in supernatant media were cultured in PneumaCult-Ex Medium (StemCell, Canada). In addition, cells from NP tissues were exposed to $100 \mathrm{ng} / \mathrm{mL}$ rhEGF for $48 \mathrm{~h}$. After reaching about $70 \% \sim 80 \%$ confluence, cells were digested with Accutase (StemCell, Canada) for about $5 \mathrm{~min}$, and then seeded on Transwell chamber $(0.4 \mu \mathrm{m}$ pore size; Corning, USA). To induce cell differentiation at ALI culture, the medium at the basal side of Transwell was replaced by PneumaCult-ALI Medium kit (StemCell, Canada) and the medium at the apical side was removed. PHNECs were fully mature after cultured for 21 days in ALI.
To identify the ALI cultured cells, HE, AB-PAS and immunofluorescence staining were applied. The expression of tubulin, p63, and mucin5AC (the marker of ciliated cell, basal cell and mucous cell) were detected by immunofluorescence. ${ }^{41}$ The slices were photographed with an inverted microscope (Leica, Germany). The systematic workflow of the study is shown in Figure 1.

\section{Statistical Analysis}

All experimental data were presented as means \pm SD. Comparisons were calculated using one-way ANOVA or Student's $t$-test. All statistical analyses were performed using GraphPad prism 8.0 software. P value $<0.05$ was considered statistically significant.

\section{Results}

\section{Identification of DEGs and Key Gene}

In dataset GSE36830, a total of 1035 DEGs were identified between the NP tissues and health controls by $\mathrm{R}$ software $(|\operatorname{logFC}|>1, p<0.05)$, and the top 50 DEGs were shown in the heatmap (Figure 2A). Among them, 661 genes were up-regulated and 374 genes were down-regulated (Figure 2B). The PPI networks of DEGs were constructed based on the STRING database, and the cytohubba plug-in of Cytoscape was applied to identify the top 10 key genes (TYROBP, IL10, CD86, ITGB2, SPI1, EGF, LILRB2, CSF1R, CCR7, and FCGR2B) (Figure 2C and D). Only the expression of EGF was down-regulated in NP group among the top 10 key genes (Supplemental Figure 1). In addition, the DEGs and identified key genes between the UT of CRSsNP and NP of CRSwNP group, and those between the UT of CRSwNP and NP of CRSwNP group are shown in Supplemental Figure 2.

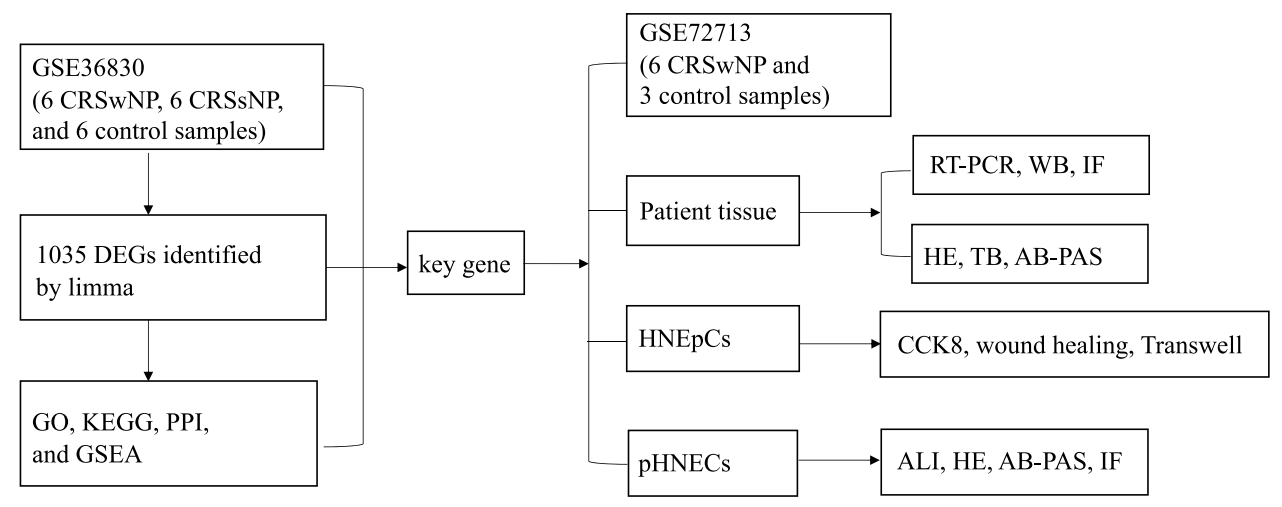

Figure I Workflow diagram of data collection and analysis. 

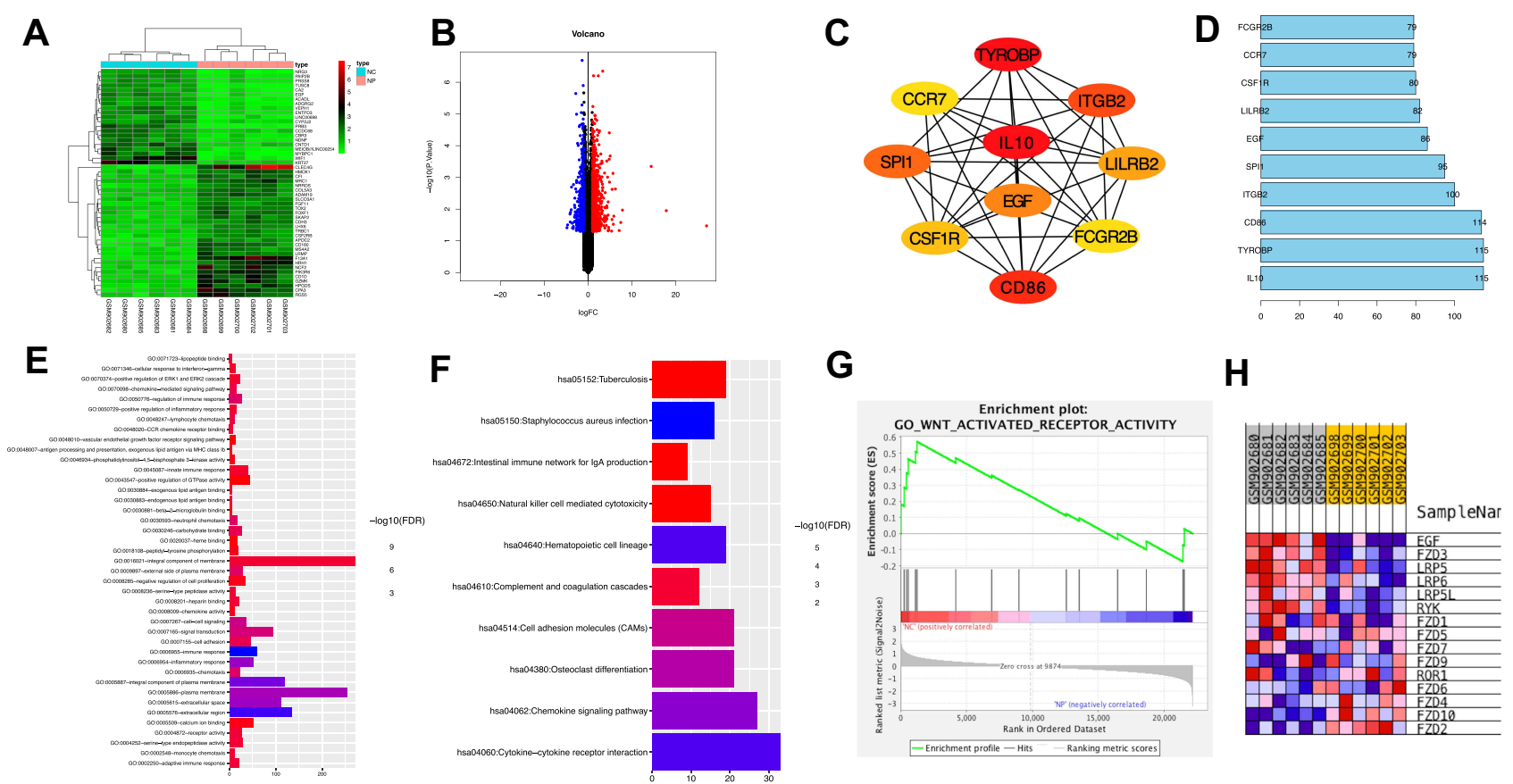

Figure 2 The results of bioinformatics analysis. (A) The top 50 DEGs identified by R software. The highly expressed genes in NP group were represented by the red areas and lowly expressed were represented by the green areas. (B) Volcano plot. Red dots represent the up-regulated genes and blue dots represent the down-regulated genes. (C) The top 10 key genes of DEGs identified by cytohubba. (D) The degree of the top 10 key genes was listed by R software. (E) GO functional enrichment result of DEGs. (F) KEGG functional enrichment result of DEGs. (G) EGF was highly enriched in "WNT-activated receptor activity" (ES=0.57, NES =I.65, $p<0.05)$ according to GSEA. (H) The heatmap of GSEA showed genes distribution of "WNT-activated receptor activity".

Abbreviations: DEGs, differentially expressed genes; NP, nasal polyps; GO, Gene Ontology; KEGG, Kyoto Encyclopedia of Genes and Genomes; GSEA, gene set enrichment analysis; ES, enrichment score; NES, normalized enrichment score.

\section{GO and KEGG Analyses}

DAVID online tool was used for functional analysis of the 1035 DEGs between the NP tissues and health controls. GO functional enrichment analysis showed that the DEGs were mainly significantly enriched in immune response, extracellular region, and integral component of plasma membrane (top 3) (Figure 2E). Meanwhile, KEGG analysis showed that they were mainly significantly enriched in Staphylococcus aureus infection, Cytokine-cytokine receptor interaction, and Hematopoietic cell lineage (top 3) (Figure 2F).

\section{GO Enrichment Analysis of All Detected} Genes

According to GSEA, EGF was highly enriched in "Wntactivated receptor activity" (Figure 2G and $\mathrm{H}$ ). The enrichment score $(\mathrm{ES})=0.57$, and the normalized enrichment score $(\mathrm{NES})=1.65(p<0.05)$.

\section{The Validation of EGF in GSE727/3 Dataset and Patient Tissues}

The expression of EGF was decreased in NP tissues in GSE72713 dataset (Figure 3A). However, there were only
3 normal controls and 6 CRSwNP patients in GSE72713. To make the results more credible, patient tissues were collected in our hospital. The RT-PCR and WB results revealed that the expression levels of EGF mRNA and protein were significantly down-regulated in NP tissues compared with the normal controls $(p<0.01)$ (Figure 3B-D).

\section{Histological Staining Results}

The HE, AB-PAS, and immunofluorescence staining showed that the number of eosinophils, mucous cells, and mast cells were significantly increased in NP tissues (Figure 3E-G). In addition, the results of immunofluorescence staining also revealed that the expression levels of EGF and ZO-1 were down-regulated in NP tissues (Figure $3 \mathrm{H}$ and I). EGF protein was mainly expressed in the ciliated cells and basal cells (Figure 3J).

\section{EGF Regulates Proliferation and Migration of HNEpCs}

To investigate the role of EGF in the proliferation and migration of HNEpCs, cells were treated with rhEGF. 


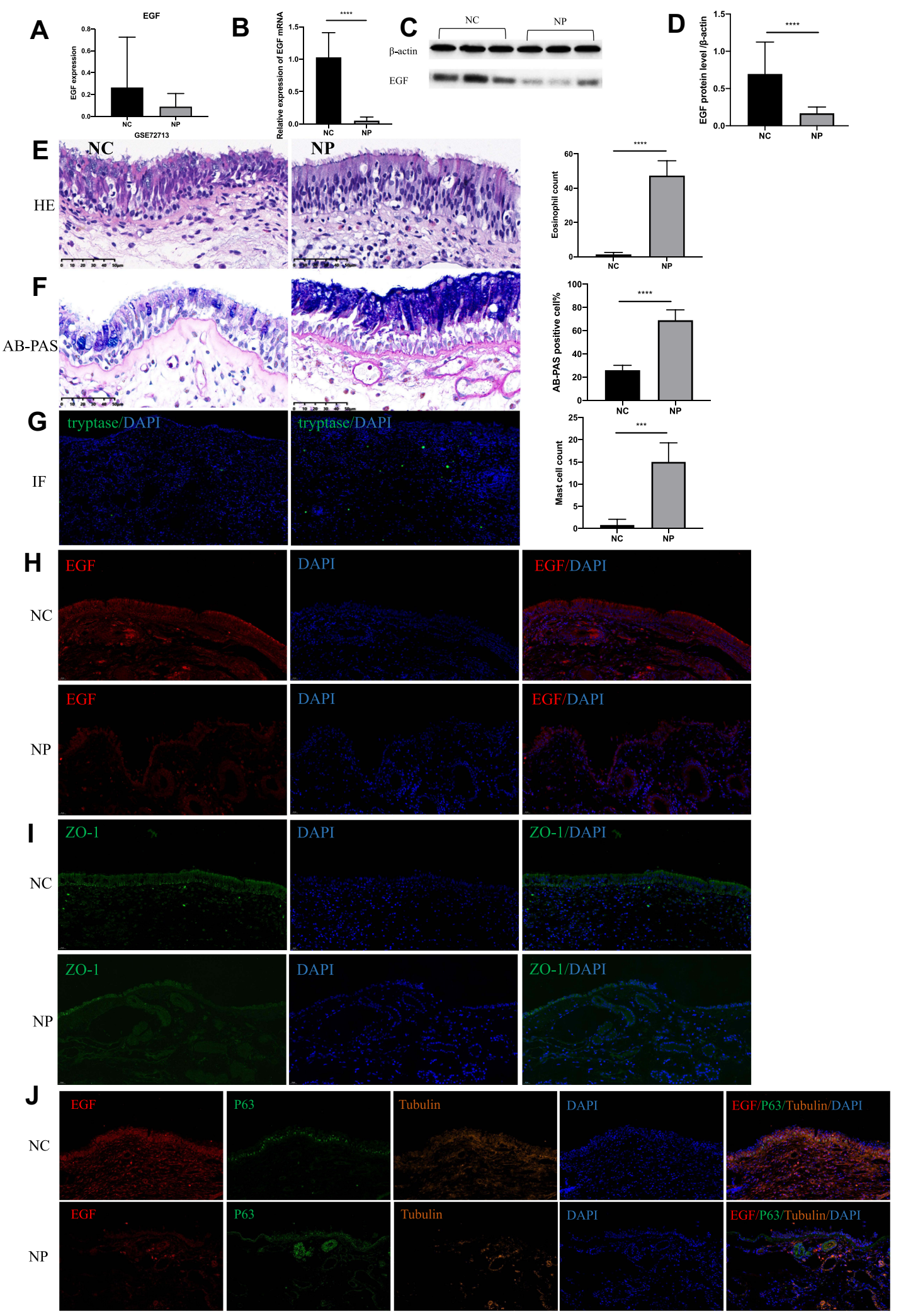

Figure 3 The expression level of EGF and the histologic appearance of nasal tissues. (A) The mRNA level of EGF were down-regulated in NP group in GSE727I3. (B) The mRNA level of EGF were down-regulated in NP tissues of CRSwNP patients. (C) Western blot result of EGF in nasal tissues. (D) Densitometric analysis of EGF in nasal tissues. (E) Infiltration of eosinophils was examined using HE staining. (F) The hyperplasia of mucous cells was examined using AB-PAS staining. (G) Infiltration of mast cells was examined using immunofluorescence staining. (H) Immunofluorescence staining detect the expression of EGF in nasal tissues. (I) Immunofluorescence staining detect the expression of ZO-I in nasal tissues. (J) Immunofluorescence staining localize the expression of EGF, P63, and Tubulin in nasal tissues. $* * * * * p<0.000 \mathrm{I}$, $* * * p<0.00 \mathrm{I}$. (Original magnification, $\times 400$ ). Abbreviations: NP, nasal polyps; HE, hematoxylin and eosin; AB-PAS, Alcian blue-periodic acid Schiff; IF, immunofluorescence staining. 
The results of wound healing, transwell migration, and CCK-8 assays showed that rhEGF can promote proliferation and migration of HNEpCs (Figure 4A-C).

\section{EGF Regulates the Expression of ZO-I}

To further investigate the role of EGF in CRS, NP tissues and health controls were obtained and pHNECs were cultured. Cytomorphology of pHNECs was observed under optical microscope (Figure 5A). Cells were cultured in ALI for about 21 days, then HE and AB-PAS staining were used to detect the differentiation. We can see the clear hair-like structures of ciliated cells and AB-PAS positive mucous cells (Figure 5B). Meanwhile, immunofluorescence staining revealed the positive reaction to $\mathrm{p} 63$, tubulin, and mucin5AC antibodies, which was the marker of ciliated cell, basal cell and mucous cell, respectively (Figure 5C). The expression of ZO-1 was down-regulated in pHNECs from NP tissues compared with pHNECs from health controls, while the expression of ZO-1 was up-regulated in pHNECs from NP tissues which treated with $100 \mathrm{ng} / \mathrm{mL}$ rhEGF (Figure 5D).
A

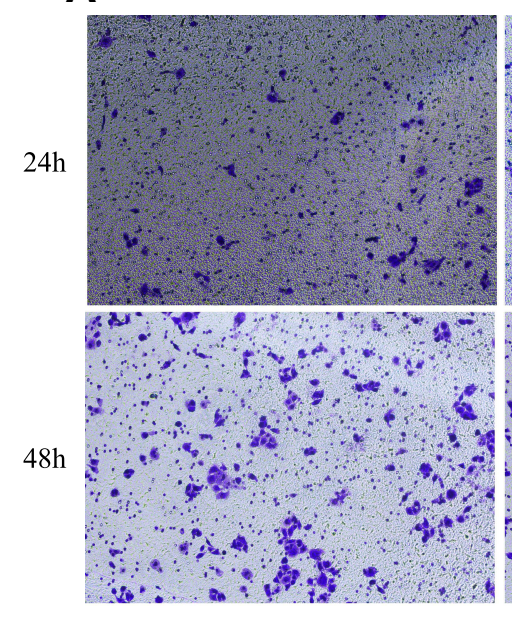

B

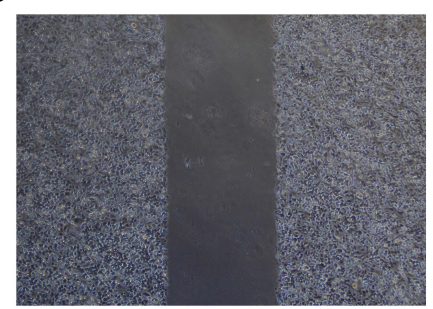

$24 \mathrm{~h}$

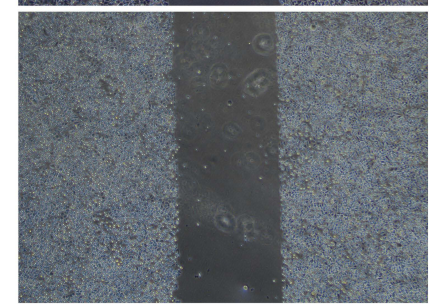

$48 \mathrm{~h}$

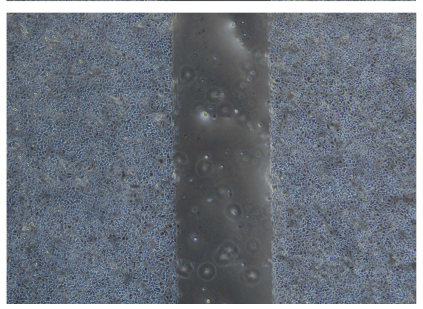

$\mathrm{rhEGF} 50 \mathrm{ng} / \mathrm{ml}$

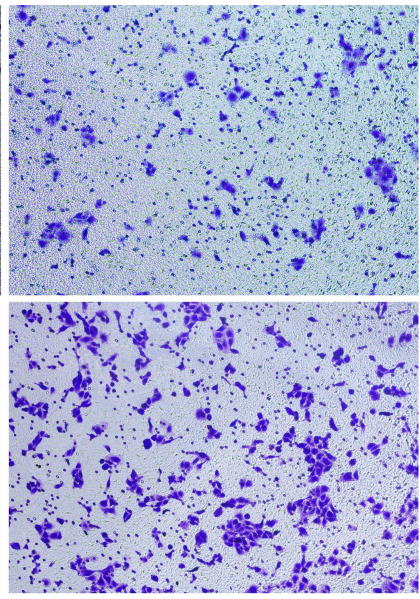

rhEGF $50 \mathrm{ng} / \mathrm{ml}$
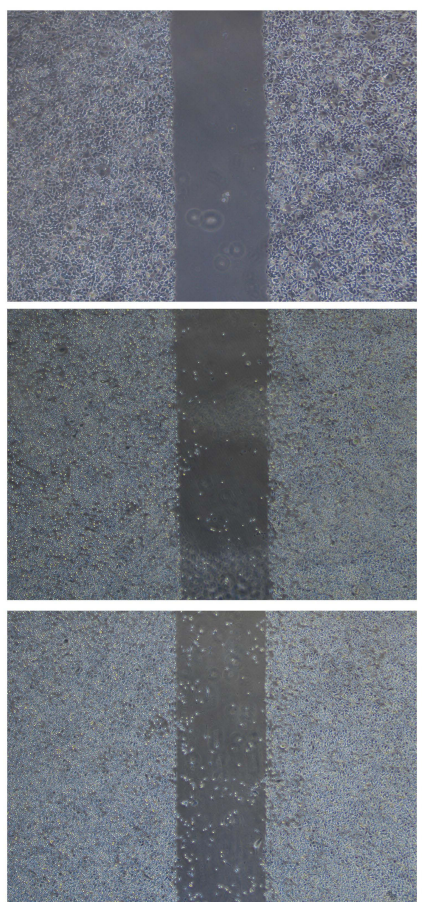

$\mathrm{rhEGF} 100 \mathrm{ng} / \mathrm{ml}$

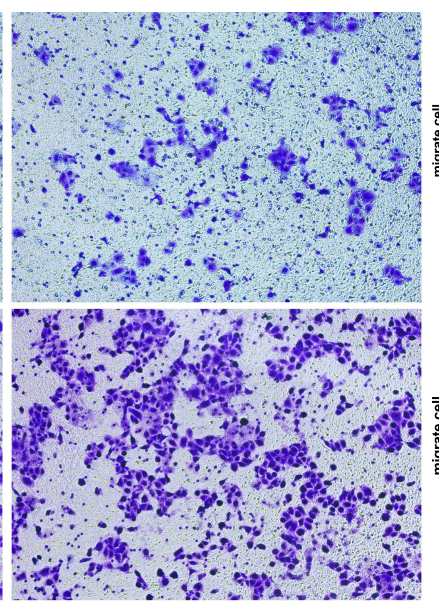

rhEGF $100 \mathrm{ng} / \mathrm{ml}$
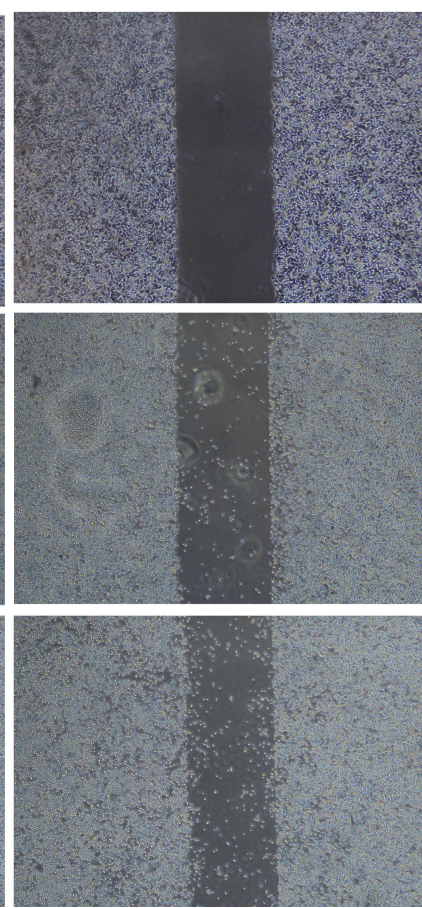

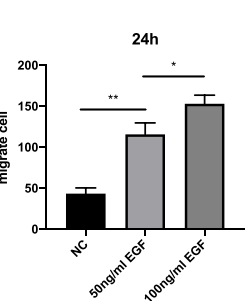

$48 \mathrm{~h}$
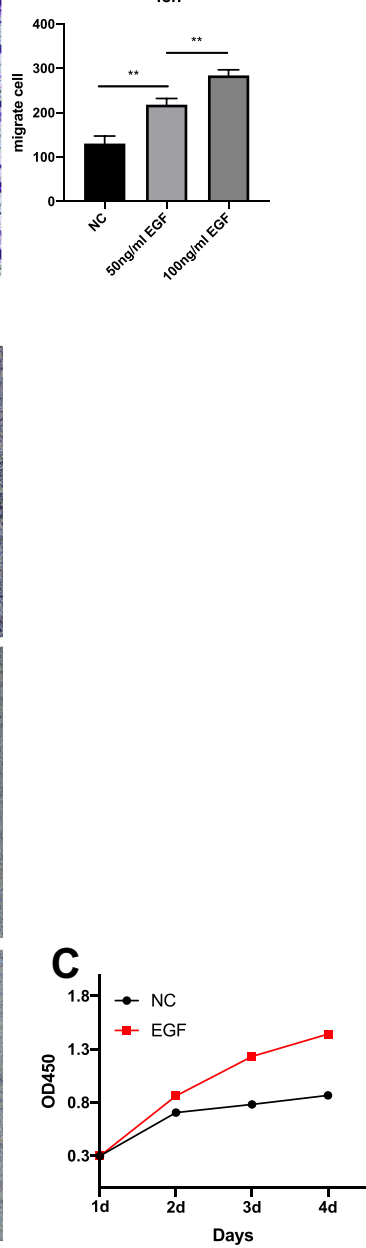

Figure 4 RhEGF promote migration and proliferation of HNEpCs. (A) Images and statistical analysis of Transwell assay. (B) Images and statistical analysis of wound healing assay. (C) Effects of rhEGF on HNEpCs proliferation. **p $<0.0$ I, ${ }^{*} p<0.05$.

Abbreviations: rhEGF, recombinant human; HNEpCs, human nasal epithelial cells. 

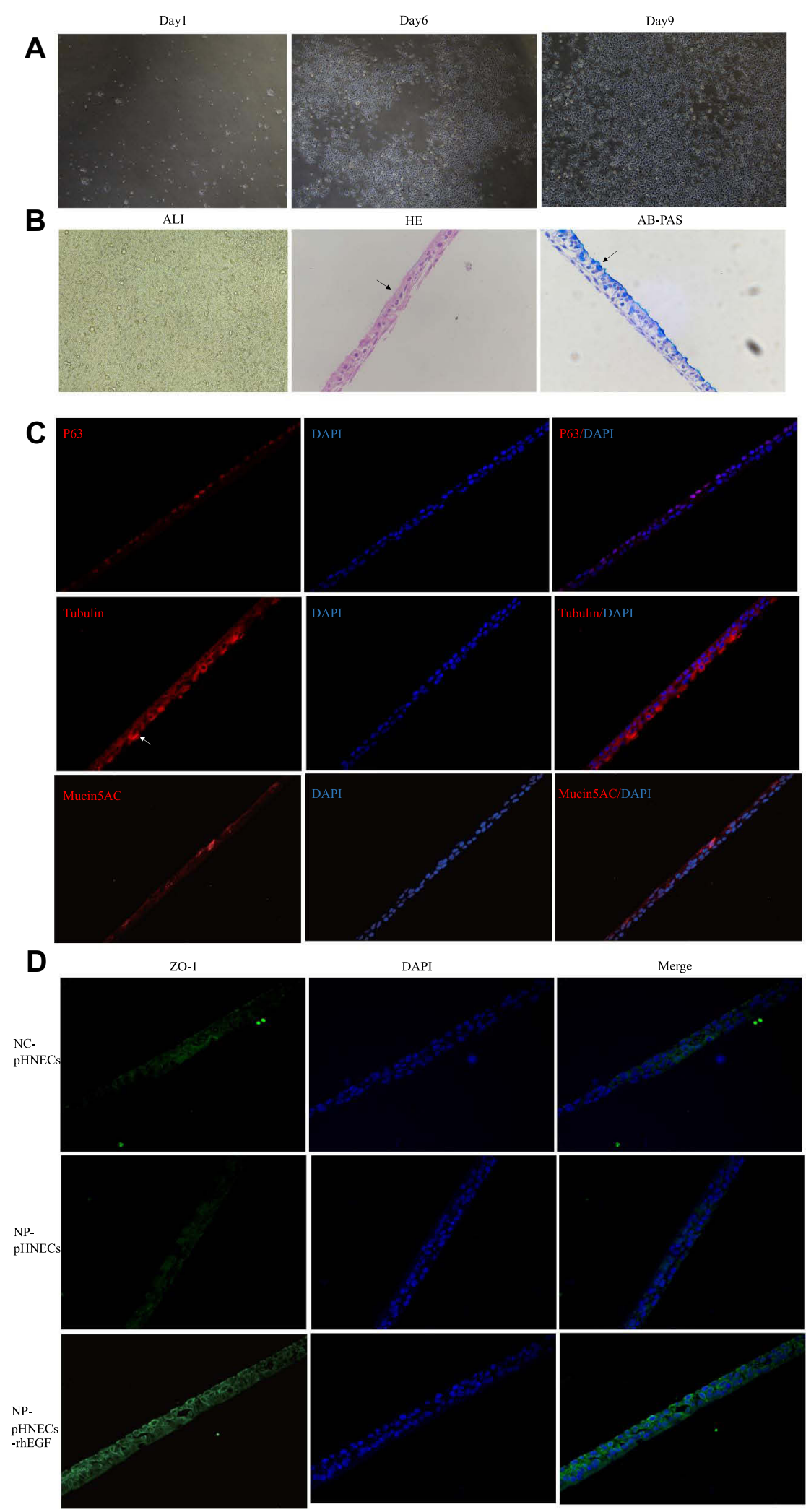

Figure 5 Identification of pHNECs and the effects of rhEGF. (A) Images of pHNECs identified with microscopy. (B) Images of pHNECs cultured in ALI (The arrow in HE shows the cilia structure; the arrow in AB-PAS shows the mucous cells). (C) Images of pHNECs cultured in ALI identified with immunofluorescence. (D) RhEGF up regulated the expression of ZO-I in pHNECs from NP tissues. (Original magnification, $\times 400$ ).

Abbreviations: pHNECs, primary human nasal epithelial cells; rhEGF, recombinant human; ALI, air-liquid interface; AB-PAS, Alcian blue-periodic acid Schiff; NP, nasal polyps. 


\section{Discussion}

In the present study, GO, KEGG and PPI analyses were applied to investigate key genes involved in the pathogenesis of CRSwNP. By GO and KEGG analyses, immune response and Staphylococcus aureus infection were found to be the most significantly enriched terms, respectively (Figure 2E and F). The heterogeneity and clinical manifestations of CRS were dependent on the selective expression of type 1,2, or 3 immune responses. ${ }^{42-44}$ Staphylococcus aureus is more usually exists in patients with CRSwNP compared with CRSsNPs, and it can be found under the epithelial surface. ${ }^{45}$ ${ }^{49}$ Staphylococcus aureus exoproducts alter epithelial repair on pHNECs significantly, and it is more obvious in the patients with nasal polyps. ${ }^{50}$ Staphylococcus aureus has a key impact on the nasal epithelium barrier and immune system in patients with CRS. ${ }^{51-59}$ According to PPI analysis, the top 10 key genes were identified by Cytohubba, among them, only EGF was down-regulated in NP tissues (Supplemental Figure 1). EGF (epidermal growth factor) is a $160 \mathrm{kDa}$ membrane glycoprotein. It is a ligand of EGF-receptor and plays important roles in cell differentiation, proliferation, and motility. ${ }^{60}$ Jacob et al indicated that EGF was significantly down-regulated in atopic dermatitis patients, and this lowexpression state may impair anti-inflammatory immune response and proliferation in the skin. ${ }^{61-64}$ Duan et al revealed that EGF was localized within $\mathrm{p} 63^{+}$basal cells in health controls, and there was a down-regulation of EGF in NP tissues. ${ }^{65}$ While, Ding et al reported an elevated level of EGF in the sinus mucosa of CRSwNP patients. ${ }^{66}$ In the present study, to detect the expression level of EGF in NP tissues and health controls, RT-PCR, WB and immunofluorescence staining analyses were applied. The results showed that the expression levels of EGF mRNA and protein were significantly down-regulated in NP tissues (Figure 3B-D and $\mathrm{H}$ ). Meanwhile, down-regulated expression of ZO-1 protein was detected in NP tissues (Figure 3I). The immunofluorescence staining results showed that EGF was localized in $\mathrm{p} 63^{+}$basal cells and ciliated cells (Figure 3J). As reported in previous study, EGF was expressed in ciliated and basal cells in bronchial epithelium. ${ }^{67}$ The decreased number of ciliated cells may be associated with the down-regulated expression of EGF in NP tissues. To further explore the effects of EGF in nasal epithelial cells, biological experiments were carried out. From the results of wound healing, Transwell migration, and CCK-8 assays, we can see that rhEGF can promote the migration and proliferation of HNEpCs in vitro (Figure 4A-C). Moreover, pHNECs were successfully cultured in ALI. The pHNECs from NP tissues have a lower expression of ZO-1 compared to those from health controls. However, the expression of ZO-1 was upregulated by treating with $100 \mathrm{ng} / \mathrm{mL}$ rhEGF (Figure 5D). As previous studies reported that there was a decrease of ZO- 1 in NP tissues of CRS. ${ }^{17}$ Sheng et al revealed that EGF downregulated the expression of ZO-1 in pancreatic cancer cells. ${ }^{68}$ However, Okuyama et al reported the ability of EGF to prevent acid-induced decrease of ZO-1 in Human esophageal epithelial cells (TE-1) ${ }^{69}$ The relationship of EGF and ZO-1 in CRS still needs further research.

In addition, according to GSEA, we found that EGF was most enriched in WNT-activated receptor activity pathway (Figure $2 \mathrm{G}$ and $\mathrm{H}$ ). Wnt signaling was found to become re-expressed in inflammatory diseases, and it played a huge part in injury repair. ${ }^{70-79}$ Boscke et al reported that Wnt signaling was up-regulated in NP tissues and this activation can promote the release of cytokines in HNEpCs. ${ }^{80}$ Meanwhile, the activation of Wnt pathway in HNEpCs can lead to the abnormal epithelial morphology and the loss of cellular differentiation. However, Whyte et al reported that Wnt signaling is responsible for the regenerating response of injured tissues. ${ }^{81}$ EGF and Wnt signaling are involved in the proliferation of intestinal epithelial stem cells and skin epithelial stem cells. ${ }^{82-88}$ EGF can mediate the proliferation of mesenchymal stem cells via Wnt/ $\beta$-catenin activation. ${ }^{89}$ As far as we know, there have been few relevant researches in CRS, and intensive study is needed to reveal the effects of EGF and Wnt signaling on nasal epithelium.

\section{Conclusion}

In conclusion, this study identified the key genes and pathways involved in CRSwNP by bioinformatics analysis, and the key gene was verified by patient samples. Meanwhile, we demonstrated the promotional effects of EGF on the proliferation and migration of HNEpCs in vitro, and EGF can lead to an increased expression of ZO-1 in pHNECs from NP tissues.

\section{Data Sharing Statement}

All datasets generated for this study are included in the article.

\section{Ethics Statement}

This study was reviewed and approved by the Eye \& ENT Hospital. 


\section{Acknowledgments}

This work was supported by the National Natural Science Foundation of China under Grant number 81700901; Shanghai Science and Technology Committee Foundation under Grant number 19411950600; the New Technologies of Endoscopic Surgery in Skull Base Tumor: CAMS Innovation Fund for Medical Sciences (CIFMS) under Grant number 2019-I2M-5-003.

\section{Author Contributions}

All authors made a significant contribution to the work reported, whether that is in the conception, study design, execution, acquisition of data, analysis and interpretation, or in all these areas; took part in drafting, revising or critically reviewing the article; gave final approval of the version to be published; have agreed on the journal to which the article has been submitted; and agree to be accountable for all aspects of the work. All authors read and approved the final manuscript.

\section{Disclosure}

The authors declare that they have no competing interests.

\section{References}

1. Hastan D, Fokkens WJ, Bachert C, et al. Chronic rhinosinusitis in Europe-an underestimated disease. A GA(2)LEN study. Allergy. 2011;66:1216-1223. doi:10.1111/j.1398-9995.2011.02646.x

2. Shi JB, Fu QL, Zhang H, et al. Epidemiology of chronic rhinosinusitis: results from a cross-sectional survey in seven Chinese cities. Allergy. 2015;70:533-539. doi:10.1111/all.12577

3. Wang X, Zhang N, Bo M, et al. Diversity of TH cytokine profiles in patients with chronic rhinosinusitis: a multicenter study in Europe, Asia, and Oceania. J Allergy Clin Immunol. 2016;138:1344-1353. doi:10.1016/j.jaci.2016.05.041

4. Workman AD, Kohanski MA, Cohen NA. Biomarkers in chronic rhinosinusitis with nasal polyps. Immunol Allergy Clin North Am. 2018;38:679-692. doi:10.1016/j.iac.2018.06.006

5. Cao PP, Li H-B, Wang B-F, et al. Distinct immunopathologic characteristics of various types of chronic rhinosinusitis in adult Chinese. J Allergy Clin Immunol. 2009;124:478-484, e471-e472. doi:10.1016/j. jaci.2009.05.017

6. Akdis CA, Bachert C, Cingi C, et al. Endotypes and phenotypes of chronic rhinosinusitis: a PRACTALL document of the European Academy of Allergy and Clinical Immunology and the American Academy of Allergy, Asthma \& Immunology. $J$ Allergy Clin Immunol. 2013;131:1479-1490. doi:10.1016/j.jaci.2013.02.036

7. Meltzer EO, Hamilos DL, Hadley JA, et al. Rhinosinusitis: establishing definitions for clinical research and patient care. Otolaryngol Head Neck Surg. 2004;131:S1-S62. doi:10.1016/j.otohns.2004.09.067

8. Fokkens WJ, Lund VJ, Mullol J, et al. EPOS 2012: European position paper on rhinosinusitis and nasal polyps 2012. A summary for otorhinolaryngologists. Rhinology. 2012;50:1-12. doi:10.4193/ Rhino12.000

9. Bachert C, Marple B, Schlosser RJ, et al. Adult chronic rhinosinusitis. Nat Rev Dis Primers. 2020;6:86. doi:10.1038/s41572-020-00218-1
10. Rosenfeld RM, Piccirillo JF, Chandrasekhar SS, et al. Clinical practice guideline (update): adult sinusitis. Otolaryngol Head Neck Surg. 2015;152:S1-S39. doi:10.1177/0194599815572097

11. Seshadri S, Lin DC, Rosati M, et al. Reduced expression of antimicrobial PLUNC proteins in nasal polyp tissues of patients with chronic rhinosinusitis. Allergy. 2012;67:920-928. doi:10.1111/j.13989995.2012.02848.x

12. Tantilipikorn P, Sompornrattanaphan M, Suwanwech T, Ngaotepprutaram P. Chronic rhinosinusitis and allergy: increased allergen sensitization versus real allergic rhinitis multimorbidity: a systematic review. Curr Allergy Asthma Rep. 2020;20:19. doi:10.1007/s11882-020-00913-9

13. Stevens WW, Schleimer RP, Kern RC. Chronic rhinosinusitis with nasal polyps. J Allergy Clin Immunol Pract. 2016;4:565-572. doi:10.1016/j.jaip.2016.04.012

14. Soyka MB, Wawrzyniak P, Eiwegger T, et al. Defective epithelial barrier in chronic rhinosinusitis: the regulation of tight junctions by IFN-gamma and IL-4. J Allergy Clin Immunol. 2012;130:1087-1096 e1010. doi:10.1016/j.jaci.2012.05.052

15. Tieu DD, Kern RC, Schleimer RP. Alterations in epithelial barrier function and host defense responses in chronic rhinosinusitis. $J$ Allergy Clin Immunol. 2009;124:37-42. doi:10.1016/j. jaci.2009.04.045

16. Kao SS, Ramezanpour M, Bassiouni A, et al. Barrier disruptive effects of mucus isolated from chronic rhinosinusitis patients. Allergy. 2020;75:200-203. doi:10.1111/all.13964

17. Schleimer RP. Immunopathogenesis of chronic rhinosinusitis and nasal polyposis. Annu Rev Pathol. 2017;12:331-357. doi:10.1146/ annurev-pathol-052016-100401

18. Zhang N, Van Crombruggen K, Gevaert E, Bachert C. Barrier function of the nasal mucosa in health and type-2 biased airway diseases. Allergy. 2016;71:295-307. doi:10.1111/all.12809

19. Schleimer RP, Kato A, Kern R, Kuperman D, Avila PC. Epithelium: at the interface of innate and adaptive immune responses. $J$ Allergy Clin Immunol. 2007;120:1279-1284. doi:10.1016/j.jaci.2007.08.046

20. Van Bruaene N, Bachert C. Tissue remodeling in chronic rhinosinusitis. Curr Opin Allergy Clin Immunol. 2011;11:8-11. doi:10.1097/ACI.0b013e32834233ef

21. Barham HP, Osborn JL, Snidvongs K, et al. Remodeling changes of the upper airway with chronic rhinosinusitis. Int Forum Allergy Rhinol. 2015;5:565-572. doi:10.1002/alr.21546

22. Kern RC, Conley DB, Walsh W, et al. Perspectives on the etiology of chronic rhinosinusitis: an immune barrier hypothesis. Am J Rhinol. 2008;22:549-559. doi:10.2500/ajr.2008.22.3228

23. Meng J, Zhou P, Liu Y, et al. The development of nasal polyp disease involves early nasal mucosal inflammation and remodelling. PLoS One. 2013;8:e82373. doi:10.1371/journal.pone.0082373

24. Brozek JL, Bousquet J, Agache I, et al. Allergic rhinitis and its impact on asthma (ARIA) guidelines-2016 revision. J Allergy Clin Immunol. 2017;140:950-958. doi:10.1016/j.jaci.2017.03.050

25. Jang YJ, Kim HG, Koo TW, Chung PS. Localization of ZO-1 and E-cadherin in the nasal polyp epithelium. Eur Arch Otorhinolaryngol. 2002;259:465-469. doi:10.1007/s00405-002-0500-z

26. Rogers GA, Beste KD, Parkos CA, et al. Epithelial tight junction alterations in nasal polyposis. Int Forum Allergy Rhinol. 2011;1:50-54. doi:10.1002/alr.20014

27. Barmeyer C, Schulzke JD, Fromm M. Claudin-related intestinal diseases. Semin Cell Dev Biol. 2015;42:30-38. doi:10.1016/j. semcdb.2015.05.006

28. Shahana S, Jaunmuktane Z, Asplund MS, Roomans GM. Ultrastructural investigation of epithelial damage in asthmatic and non-asthmatic nasal polyps. Respir Med. 2006;100:2018-2028. doi:10.1016/j.rmed.2006.02.012

29. Loxham M, Davies DE. Phenotypic and genetic aspects of epithelial barrier function in asthmatic patients. J Allergy Clin Immunol. 2017;139:1736-1751. doi:10.1016/j.jaci.2017.04.005 
30. Georas SN, Rezaee F. Epithelial barrier function: at the front line of asthma immunology and allergic airway inflammation. J Allergy Clin Immunol. 2014;134:509-520. doi:10.1016/j.jaci.2014.05.049

31. Yu XM, Li CW, Chao SS, et al. Reduced growth and proliferation dynamics of nasal epithelial stem/progenitor cells in nasal polyps in vitro. Sci Rep. 2014;4:4619. doi:10.1038/srep04619

32. Yu XM, Li CW, Li YY, et al. Down-regulation of EMP1 is associated with epithelial hyperplasia and metaplasia in nasal polyps. Histopathology. 2013;63:686-695. doi:10.1111/his.12211

33. Wang W, Gao Z, Wang H, et al. Transcriptome analysis reveals distinct gene expression profiles in eosinophilic and noneosinophilic chronic rhinosinusitis with nasal polyps. Sci Rep. 2016;6:26604. doi:10.1038/srep26604

34. Ma Y, Zheng C, Shi L. The kinase LRRK2 is differently expressed in chronic rhinosinusitis with and without nasal polyps. Clin Transl Allergy. 2018;8:8. doi:10.1186/s13601-018-0194-y

35. Nian JB, Zeng M, Zheng J, et al. Epithelial cells expressed IL-33 to promote degranulation of mast cells through inhibition on ST2/PI3K/ mTOR-mediated autophagy in allergic rhinitis. Cell Cycle. 2020;19:1132-1142. doi:10.1080/15384101.2020.1749402

36. Wlodarska M, Thaiss C, Nowarski R, et al. NLRP6 inflammasome orchestrates the colonic host-microbial interface by regulating goblet cell mucus secretion. Cell. 2014;156:1045-1059. doi:10.1016/j. cell.2014.01.026

37. Buque A, Bloy N, Perez-Lanzón M, et al. Immunoprophylactic and immunotherapeutic control of hormone receptor-positive breast cancer. Nat Commun. 2020;11:3819. doi:10.1038/s41467-020-17644-0

38. Lai X, Li X, Chang L, et al. IL-19 up-regulates mucin 5AC production in patients with chronic rhinosinusitis via STAT3 pathway. Front Immunol. 2019;10:1682. doi:10.3389/fimmu.2019.01682

39. Cheng J, Chen J, Zhao Y, et al. MicroRNA-761 suppresses remodeling of nasal mucosa and epithelial-mesenchymal transition in mice with chronic rhinosinusitis through LCN2. Stem Cell Res Ther. 2020;11:151. doi:10.1186/s13287-020-01598-7

40. Shi S, Han Y, Wang D, et al. PD-L1 and PD-1 expressed in trigeminal ganglia may inhibit pain in an acute migraine model. Cephalalgia. 2020;40:288-298. doi:10.1177/0333102419883374

41. Parra ER, Villalobos P, Behrens C, et al. Effect of neoadjuvant chemotherapy on the immune microenvironment in non-small cell lung carcinomas as determined by multiplex immunofluorescence and image analysis approaches. J Immunother Cancer. 2018;6:48. doi:10.1186/s40425-018-0368-0

42. Van Bruaene N, Pérez-Novo CA, Basinski TM, et al. T-cell regulation in chronic paranasal sinus disease. J Allergy Clin Immunol. 2008;121:1435-1441, e1431-e1433. doi:10.1016/j.jaci.2008.02.018

43. Bachert C, Zhang N, Holtappels G, et al. Presence of IL-5 protein and IgE antibodies to staphylococcal enterotoxins in nasal polyps is associated with comorbid asthma. $J$ Allergy Clin Immunol. 2010;126:962-968, e961-e966. doi:10.1016/j.jaci.2010.07.007

44. Tan BK, Klingler AI, Poposki JA, et al. Heterogeneous inflammatory patterns in chronic rhinosinusitis without nasal polyps in Chicago, Illinois. $J$ Allergy Clin Immunol. 2017;139:699-703 e697. doi:10.1016/j.jaci.2016.06.063

45. Thanasumpun T, Batra PS. Endoscopically-derived bacterial cultures in chronic rhinosinusitis: a systematic review. Am J Otolaryngol. 2015;36:686-691. doi:10.1016/j.amjoto.2015.04.010

46. Zhang Z, Adappa ND, Doghramji LJ, et al. Different clinical factors associated with Staphylococcus aureus and Pseudomonas aeruginosa in chronic rhinosinusitis. Int Forum Allergy Rhinol. 2015;5:724-733. doi:10.1002/alr.21532

47. Corriveau MN, Zhang N, Holtappels G, Van Roy N, Bachert C. Detection of Staphylococcus aureus in nasal tissue with peptide nucleic acid-fluorescence in situ hybridization. Am J Rhinol Allergy. 2009;23:461-465. doi:10.2500/ajra.2009.23.3367
48. Tan NC, Foreman A, Jardeleza C, et al. Intracellular Staphylococcus aureus: the Trojan horse of recalcitrant chronic rhinosinusitis? Int Forum Allergy Rhinol. 2013;3:261-266. doi:10.1002/alr.21154

49. Kim RJ, Yin T, Chen C-J-J, et al. The interaction between bacteria and mucosal immunity in chronic rhinosinusitis: a prospective cross-sectional analysis. Am J Rhinol Allergy. 2013;27:e183-e189. doi:10.2500/ajra.2013.27.3974

50. Valera FCP, Ruffin M, Adam D, et al. Staphylococcus aureus impairs sinonasal epithelial repair: effects in patients with chronic rhinosinusitis with nasal polyps and control subjects. J Allergy Clin Immunol. 2019;143:591-603 e593. doi:10.1016/j.jaci.2018.05.035

51. Tan NC, Cooksley CM, Roscioli E, et al. Small-colony variants and phenotype switching of intracellular Staphylococcus aureus in chronic rhinosinusitis. Allergy. 2014;69:1364-1371. doi:10.1111/ all. 12457

52. Kohanski MA, Lane AP. Sinonasal epithelial cell response to Staphylococcus aureus burden in chronic rhinosinusitis. JAMA Otolaryngol Head Neck Surg. 2015;141:341-349. doi:10.1001/ jamaoto.2014.3550

53. Gevaert E, Zhang N, Krysko O, et al. Extracellular eosinophilic traps in association with Staphylococcus aureus at the site of epithelial barrier defects in patients with severe airway inflammation. J Allergy Clin Immunol. 2017;139:1849-1860 e1846. doi:10.1016/j. jaci.2017.01.019

54. Teufelberger AR, Nordengrün M, Braun H, et al. The IL-33/ST2 axis is crucial in type 2 airway responses induced by Staphylococcus aureus-derived serine protease-like protein D. $J$ Allergy Clin Immunol. 2018;141:549-559 e547. doi:10.1016/j.jaci.2017.05.004

55. Malik Z, Roscioli E, Murphy J, et al. Staphylococcus aureus impairs the airway epithelial barrier in vitro. Int Forum Allergy Rhinol. 2015;5(6):551-556. doi:10.1002/alr.21517

56. Kim CS, Jeon S-Y, Min Y-G, et al. Effects of beta-toxin of Staphylococcus aureus on ciliary activity of nasal epithelial cells. Laryngoscope. 2000;110:2085-2088. doi:10.1097/00005537200012000-00021

57. Eiffler I, Behnke J, Ziesemer S, Muller C, Hildebrandt JP. Staphylococcus aureus alpha-toxin-mediated cation entry depolarizes membrane potential and activates p38 MAP kinase in airway epithelial cells. Am J Physiol Lung Cell Mol Physiol. 2016;311:L676-L685. doi:10.1152/ajplung.00090.2016

58. Hermann I, Räth S, Ziesemer S, et al. Staphylococcus aureus hemolysin A disrupts cell-matrix adhesions in human airway epithelial cells. Am J Respir Cell Mol Biol. 2015;52:14-24. doi:10.1165/ rcmb.2014-0082OC

59. LeMessurier KS, Tiwary M, Morin NP, Samarasinghe AE. Respiratory barrier as a safeguard and regulator of defense against influenza A virus and Streptococcus pneumoniae. Front Immunol. 2020;11:3. doi:10.3389/fimmu.2020.00003

60. Burgel PR, Nadel JA. Roles of epidermal growth factor receptor activation in epithelial cell repair and mucin production in airway epithelium. Thorax. 2004;59:992-996. doi:10.1136/thx.2003.01 8879

61. Jacob M, Bin Khalaf D, Alhissi S, et al. Quantitative profiling of cytokines and chemokines in DOCK8-deficient and atopic dermatitis patients. Allergy. 2019;74:370-379. doi:10.1111/all.13610

62. Pastore S, Mascia F, Mariani V, Girolomoni G. The epidermal growth factor receptor system in skin repair and inflammation. $J$ Invest Dermatol. 2008;128:1365-1374. doi:10.1038/sj. jid.5701184

63. Sinha A, Nightingale J, West KP, Berlanga-Acosta J, Playford RJ. Epidermal growth factor enemas with oral mesalamine for mild-tomoderate left-sided ulcerative colitis or proctitis. $N$ Engl J Med. 2003;349:350-357. doi:10.1056/NEJMoa013136 
64. Brown GL, Nanney LB, Griffen J, et al. Enhancement of wound healing by topical treatment with epidermal growth factor. $N \mathrm{Engl}$ J Med. 1989;321:76-79. doi:10.1056/NEJM198907133210203

65. Duan C, Li CW, Zhao L, et al. Differential expression patterns of EGF, EGFR, and ERBB4 in nasal polyp epithelium. PLoS One. 2016;11:e0156949. doi:10.1371/journal.pone.0156949

66. Ding GQ, Zheng CQ, Bagga SS. Up-regulation of the mucosal epidermal growth factor receptor gene in chronic rhinosinusitis and nasal polyposis. Arch Otolaryngol Head Neck Surg. 2007;133:1097-1103. doi:10.1001/archotol.133.11.1097

67. Marinas AE, Ciurea P, Margaritescu C, Cotoi OS. Expression of epidermal growth factor (EGF) and its receptors (EGFR1 and EGFR2) in chronic bronchitis. Rom $J$ Morphol Embryol. 2012;53:957-966.

68. Sheng W, Shi X, Lin Y, et al. Musashi2 promotes EGF-induced EMT in pancreatic cancer via ZEB1-ERK/MAPK signaling. J Exp Clin Cancer Res. 2020;39:16. doi:10.1186/s13046-020-1521-4

69. Okuyama M, Fujiwara Y, Tanigawa T, et al. Roles of ZO-1 and epidermal growth factor in esophageal epithelial defense against acid. Digestion. 2007;75:135-141. doi:10.1159/000106454

70. Kugler MC, Joyner AL, Loomis CA, Munger JS. Sonic hedgehog signaling in the lung. From development to disease. Am J Respir Cell Mol Biol. 2015;52:1-13. doi:10.1165/rcmb.2014-0132TR

71. Konigshoff M, Balsara N, Pfaff E-M, et al. Functional Wnt signaling is increased in idiopathic pulmonary fibrosis. PLoS One. 2008;3: e2142. doi:10.1371/journal.pone.0002142

72. Choy DF, Modrek B, Abbas AR, et al. Gene expression patterns of Th2 inflammation and intercellular communication in asthmatic airways. J Immunol. 2011;186:1861-1869. doi:10.4049/jimmunol.10 02568

73. Chilosi M, Poletti V, Zamò A, et al. Aberrant Wnt/beta-catenin pathway activation in idiopathic pulmonary fibrosis. Am J Pathol. 2003;162:1495-1502. doi:10.1016/s0002-9440(10)64282-4

74. Aumiller V, Balsara N, Wilhelm J, Gunther A, Konigshoff M. WNT/ beta-catenin signaling induces IL-1beta expression by alveolar epithelial cells in pulmonary fibrosis. Am J Respir Cell Mol Biol. 2013;49:96-104. doi:10.1165/rcmb.2012-0524OC

75. Konigshoff M, Kramer M, Balsara N, et al. WNT1-inducible signaling protein-1 mediates pulmonary fibrosis in mice and is upregulated in humans with idiopathic pulmonary fibrosis. $J$ Clin Invest. 2009;119:772-787. doi:10.1172/JCI33950

76. Konigshoff M, Eickelberg O. WNT signaling in lung disease: a failure or a regeneration signal? Am J Respir Cell Mol Biol. 2010;42:21-31. doi:10.1165/rcmb.2008-0485TR
77. Halleskog C, Mulder J, Dahlström J, et al. WNT signaling in activated microglia is proinflammatory. Glia. 2011;59:119-131. doi:10.1002/glia.21081

78. Sen M, Lauterbach K, El-Gabalawy H, et al. Expression and function of wingless and frizzled homologs in rheumatoid arthritis. Proc Natl Acad Sci U S A. 2000;97:2791-2796. doi:10.1073/pnas.050574297

79. Blumenthal A, Ehlers S, Lauber J, et al. The Wingless homolog WNT5A and its receptor Frizzled-5 regulate inflammatory responses of human mononuclear cells induced by microbial stimulation. Blood. 2006;108:965-973. doi:10.1182/blood-2005-12-5046

80. Boscke R, Vladar EK, Könnecke M, et al. Wnt signaling in chronic rhinosinusitis with nasal polyps. Am J Respir Cell Mol Biol. 2017;56:575-584. doi:10.1165/rcmb.2016-0024OC

81. Whyte JL, Smith AA, Helms JA. Wnt signaling and injury repair. Cold Spring Harb Perspect Biol. 2012;4:a008078. doi:10.1101/ cshperspect.a008078

82. Fatehullah A, Tan SH, Barker N. Organoids as an in vitro model of human development and disease. Nat Cell Biol. 2016;18:246-254. doi: $10.1038 / \mathrm{ncb} 3312$

83. Hsu YC, Li L, Fuchs E. Emerging interactions between skin stem cells and their niches. Nat Med. 2014;20:847-856. doi:10.1038/ nm.3643

84. Lindemans CA, Calafiore M, Mertelsmann AM, et al. Interleukin-22 promotes intestinal-stem-cell-mediated epithelial regeneration. Nature. 2015;528:560-564. doi:10.1038/nature16460

85. Barker N, van Es JH, Kuipers J, et al. Identification of stem cells in small intestine and colon by marker gene Lgr5. Nature. 2007;449:1003-1007. doi:10.1038/nature06196

86. Sato T, van Es JH, Snippert HJ, et al. Paneth cells constitute the niche for Lgr5 stem cells in intestinal crypts. Nature. 2011;469:415-418. doi:10.1038/nature09637

87. Bielefeld KA, Amini-Nik S, Alman BA. Cutaneous wound healing: recruiting developmental pathways for regeneration. Cell Mol Life Sci. 2013;70:2059-2081. doi:10.1007/s00018-012-1152-9

88. Gurtner GC, Werner S, Barrandon Y, Longaker MT. Wound repair and regeneration. Nature. 2008;453:314-321. doi:10.1038/ nature07039

89. Knight C, James S, Kuntin D, et al. Epidermal growth factor can signal via beta-catenin to control proliferation of mesenchymal stem cells independently of canonical Wnt signalling. Cell Signal. 2019;53:256-268. doi:10.1016/j.cellsig.2018.09.021
Journal of Inflammation Research

\section{Publish your work in this journal}

The Journal of Inflammation Research is an international, peerreviewed open-access journal that welcomes laboratory and clinical findings on the molecular basis, cell biology and pharmacology of inflammation including original research, reviews, symposium reports, hypothesis formation and commentaries on: acute/chronic inflammation; mediators of inflammation; cellular processes; molecular mechanisms; pharmacology and novel anti-inflammatory drugs; clinical conditions involving inflammation. The manuscript management system is completely online and includes a very quick and fair peerreview system. Visit http://www.dovepress.com/testimonials.php to read real quotes from published authors. 